\title{
BMJ Open Associations between neighbourhood greenness and asthma in preschool children in Kaunas, Lithuania: a case-control study
}

Sandra Andrusaityte, ${ }^{1}$ Regina Grazuleviciene, ${ }^{1}$ Jolanta Kudzyte, ${ }^{2}$ Asta Bernotiene, ${ }^{2}$ Audrius Dedele, ${ }^{1}$ Mark J Nieuwenhuijsen ${ }^{3,4}$

To cite: Andrusaityte S, Grazuleviciene R, Kudzyte J, et al. Associations between neighbourhood greenness and asthma in preschool children in Kaunas, Lithuania: a case-control study. BMJ Open 2016;6:e010341. doi:10.1136/bmjopen-2015010341

- Prepublication history and additional material is available. To view please visit the journal (http://dx.doi.org/ 10.1136/bmjopen-2015010341).

Received 23 October 2015 Revised 23 February 2016 Accepted 11 March 2016

CrossMark

\section{ABSTRACT}

Objectives: The aim of this study was to investigate the associations between surrounding greenness levels and asthma among children, and to explore a possible change of this association by the distance of the residence to a city park.

Design: A nested case-control study.

Setting: Children aged 4-6 years residing at their current address since birth in Kaunas, Lithuania, whose mothers were recruited in 2007-2009 to the KANC newborns cohort study.

Participants: The participants were 1489 children whose parents in 2012-2013 filled in the questionnaires and agreed to participate in the study.

Primary and secondary outcome measures: We estimated clinically diagnosed asthma risk factors. The surrounding greenness was measured as the average of the satellite-based Normalised Difference Vegetation Index (NDVI) within the buffers of 100,300 and $500 \mathrm{~m}$ from each child's home address, and the distance to a city park was defined as the distance to the nearest city park. Multivariate logistic regression was performed to study the relationship between the greenness exposures and asthma adjusted for relevant covariates. Results: An increase in the NDVI (>median) in buffers of 100,300 and $500 \mathrm{~m}$ was associated with a slightly increased risk of asthma, while an IQR increase in NDVI-100 m statistically significantly increased the risk of asthma (OR 1.43, 95\% Cl 1.10 to 1.85). The stratified analysis by surrounding greenness revealed indications of stronger associations for children with higher surrounding greenness (NDVI-100>median) and those living farther away from parks $(>1000 \mathrm{~m})$, compared to NDVI-100 $\leq$ median and the distance to a city park > $1000 \mathrm{~m}$ (OR 1.47, 95\% Cl 0.56 to 3.87 ).

Conclusions: A higher level of the surrounding greenness was associated with a slightly increased relative risk of asthma in children. Further investigation is needed to elucidate the influence of city parks and neighbourhood greenness levels on asthma.

\section{INTRODUCTION}

Asthma is the most prevalent chronic disease among children. Over the past decades, the

\section{Strengths and limitations of this study}

- The current nested case-control study had the advantage of using a large number of covariates gathered during the interview, and the objective individual-level estimation of exposure to green spaces buffers around the home addresses and major ambient air pollutants.

- This is the first case-control study demonstrating the positive associations between a greater quantity of greenness in the $100 \mathrm{~m}$ buffer size of the home, assessed at an individual level, and the increased risk of asthma in children aged 4 -6 years residing at their current address since birth.

- The analysis of the joint effect of surrounding greenness and distance to park on asthma risk, controlling for relevant covariates and fine particulate matter (PM2.5), and ambient concentrations of nitrogen dioxide $\left(\mathrm{NO}_{2}\right)$ showed a slight additive effect on the strength of association; therefore, further investigations are needed to confirm this nested case-control study's results.

prevalence of asthma has progressively increased in the industrialised world and in developing regions. ${ }^{1}{ }^{2}$ There is a large geographical variation in the prevalence of asthma ranging from less than $2 \%$ to more than $20 \%$ in some countries. ${ }^{34}$ The majority of the causative agents of asthma in children remain uncertain and need clarification. Asthma most likely depends on a number of interacting factors, including genetic, behavioural and environmental risk factors, ${ }^{5-8}$ including long-term exposure to urban air pollutants emitted by traffic. ${ }^{9}$

During the past decade, more attention has been devoted to studies on the impact of the surrounding environment on allergies and asthma, seeking to elucidate the role of urban green spaces in childhood chronic diseases. $^{1011}$ 
Epidemiological data on the influence of green spaces on allergy and asthma in children are limited and inconsistent. While some studies have reported an unfavourable influence of green spaces on the prevalence of asthma and the exacerbation of allergic conditions through production of pollen, ${ }^{10}{ }^{12}$ others have reported no relationships between greenery assessed as the Normalised Difference Vegetation Index (NDVI), canopy cover and asthma. ${ }^{13}{ }^{14}$ A protective effect of the green environment around homes on the risk of atopic sensitisation in children was also found to be possible due to increased biodiversity. ${ }^{1516}$ There is mounting evidence that the close distance from the place of residence to city parks and visiting green space has benefits for people's health associated with physical activity, social coherence and stress reduction pathways; ${ }^{17-19}$ however, the evidence of causal relationship between surrounding greenness and asthma in children is inadequate.

Inconsistent associations between green space exposure and childhood asthma have stimulated studies on the relations between the surrounding greenness levels, the distance from the place of residence to city parks and asthma. This is the first study in Eastern Europe to evaluate the long-term impact of quantified greenness levels in the urban environment on the risk of asthma in 4-6-year-old children. In the present study, using individual-level data of a population-based sample and adjusting for important risk factors for asthma, we investigated the associations between objectively estimated residential greenness levels as the NDVI, residential distance to the nearest city park ( $>1$ hectare (ha)), and the number of children clinically diagnosed with asthma controlling for various covariates. Furthermore, in the stratified analysis, we investigated the joint effect interaction between surrounding greenness, distance to a city park and the risk of asthma in children controlling for PM2.5 and $\mathrm{NO}_{2}$ influence.

\section{MATERIALS AND METHODS}

This nested case-control study was conducted as part of the Positive Health Effects of the Natural Outdoor Environment in Typical Populations in Different Regions in Europe (PHENOTYPE) project funded by the European Commission Seventh Framework Programme. ${ }^{11}$ We used the data of Kaunas city pregnant women who were recruited in 2007-2009 to the KANC newborns cohort study. A detailed description of the cohort study has been described previously. ${ }^{20}$ In 2012 2013, we invited the KANC cohort of 3294 mothers and their 4-6-year-old children to participate in this study. The participants of this research were 1489 children whose mothers did not change their residence address from the pregnancy, filled in the questionnaires sent by post and agreed to participate in the study. A few missing data were specified by telephone. Parental informed consent was obtained from all participants.
Questionnaire responses by parents or guardians were used to categorise children's basic information, medical history, family history, personal habits, children's height and weight and housing and environmental conditions. Responses to the standardised International Study of Asthma and Allergies in Childhood (ISAAC) questionnaire completed by parents were used to identify children with asthma. Childhood asthma was identified by an affirmative response to the question: 'Has you child ever had doctor-diagnosed asthma?' Cases $(n=112)$ were children with clinically diagnosed asthma. Controls $(n=1377)$ were children without asthma.

\section{Assessment of exposure to green spaces}

Exposure to green spaces was objectively estimated for every child's home address using a standardised protocol and assuming that a shorter distance to a city park or a higher NDVI represents a greater exposure to green spaces. In 2012-2013, all children's addresses were geocoded to the exact address according to the street name and house number, and the participants who had lived at their current address since birth at the time of the study were included. Kaunas city green space was defined by LANDSAT_5 Thematic Mapper (TM) images at $30 \mathrm{~m} \times 30 \mathrm{~m}$ resolution retrievals and the NDVI was assigned to individuals' place of residence. The map of the NDVI was generated using the image that was obtained during the maximum vegetation period for our study region in July 2011. During the years 2011-2013, Standardised Precipitation Index in Kaunas was optimal and there was no significant yearly variation impacting green space exposure. Mean NDVI values of a straight-line buffer were calculated as estimations of the level of greenness within the immediately accessible neighbourhood $(100,300$ and $500 \mathrm{~m})$ of participants' home where various kind of pollen may be expected.

Using the Urban Atlas data for Kaunas city, we estimated the straight-line distance from every participant's home to the nearest city park larger than 1 ha with infrastructure for recreation. In Kaunas, only municipality parks greater than 1 ha have infrastructure for recreation, and therefore all of them were included in the study. To measure park accessibility, the straight-line distance variable was suggested for use in PHENOTYPE epidemiological studies seeking to receive comparable results and is easy to calculate. We constructed a binary variable (yes/no) indicating whether the child's residential address was located within $1000 \mathrm{~m}$ from a park-having a green space within a 15 min walk from home, according to the European Commission recommendation. ${ }^{21}$

Most of the parks had $65 \%$ of the area covered with trees. In the parks and squares, 195 species and cultivars of introduced ligneous plants are registered (42 are pinophyta, 153 are magnoliophyta). ${ }^{22}$ All the parks are open to the public, without fencing and have access from all sides, and offer similar recreation opportunities (eg, walking, jogging, rollerblading, physical training or 
resting on the bench) and locations (located among residential homes or establishments), and close to public transport lines (5-10 min by walk) producing good possibility contact of children with environmental biodiversity. To evaluate the possibility that ambient air pollution may confound associations between green spaces and asthma, we used Land Use Regression (LUR) models and modelled home address-specific measures of PM2.5 and ambient concentrations of $\mathrm{NO}_{2}$. A detailed description of the LUR models has been described previously. ${ }^{23}$ During the statistical analysis, exposure to PM2.5 and $\mathrm{NO}_{2}$ was categorised by median.

\section{Statistical analysis}

We used $\chi^{2}$ and univariate logistic regression analyses to compare the values and frequencies of the baseline characteristics by the studied children's asthma status. Predictor variables whose univariate test showed a statistically significant association $(p<0.05)$ with the outcome - or those that changed the adjusted ORs (aOR) by $10 \%$ or more-were retained for inclusion in multiple logistic regression analyses. The NDVI, our indicator of residential greenness, was modelled both as a continuous (IQR) and categorical (by median) measure. We conducted a sensitivity analysis for asthma outcome. Using logistic regression analysis, we estimated the association between residential greenness in 100, 300 and $500 \mathrm{~m}$ buffers by median and IQR and asthma as crude and adjusted ORs (aOR) with 95\% CIs (CI). To determine how the associations between residential surrounding greenness and asthma changed on the basis of the distance to parks, the joint effect of the NDVI- $100 \mathrm{~m}$ (100 $\mathrm{m}$ buffer around each maternal home) median and a $1000 \mathrm{~m}$ distance to a park was assessed by including an interaction term in the logistic regression controlling for covariates that may influence the risk of asthma. ORs were adjusted for individual-level mother's age at childbirth, maternal education, parental asthma, maternal smoking during pregnancy, breastfeeding, antibiotic use during the first year of life, keeping a cat during the past 12 months, living in a flat and yearly mean of ambient PM2.5 and $\mathrm{NO}_{2}$. All statistical analyses were performed using SPSS software V.18.0.

\section{RESULTS}

\section{Characteristics of the study population}

In 2012-2013, we were able to geocode home addresses and estimate residential greenness exposure for 14894 -6-year-old children (participants, response rate 45.2\%) of the 3294 KANC newborns cohort whose mothers returned questionnaires. The demographic variables of those women who did not respond to the questionnaire (non-participants) were not statistically significantly different from the participants with regard to the birth outcomes and other characteristics (see online supplementary file S1). There was no difference in the residence distance to the nearest city park between study participants and non-participants groups. Of the 1489 study children with complete data, $81.7 \%$ had homes located within $1000 \mathrm{~m}$ from the nearest city park (10 -15 min walking distance) (figure 1).

The mean surrounding greenness level (NDVI) is presented in figure 2. The medians (IQR) of the mean NDVI across the buffers of 100,300 and $500 \mathrm{~m}$ around the places of residence were $0.553(0.110), 0.548(0.109)$ and $0.547(0.116)$, respectively. The mean annual residential greenness values of the 25th, the 50th and the 75 th centiles are presented in table 1 . The median (minimum and maximum) of ambient $\mathrm{NO}_{2}$ was $15.85 \mu \mathrm{g} / \mathrm{m}^{3}\left(8.85-31.05 \mu \mathrm{g} / \mathrm{m}^{3}\right)$ and PM2.5-20.44 $\mu \mathrm{g} /$ $\mathrm{m}^{3}\left(15.83-36.09 \mu \mathrm{g} / \mathrm{m}^{3}\right)$ for residential addresses.

Physician-diagnosed asthma was reported in 112 (7.5\%) children, of whom $91(81.3 \%)$ were living within the $1000 \mathrm{~m}$ buffer zone of the nearest city park.

The descriptive statistics for the characteristics of asthmatic and non-asthmatic children and the prevalence of the investigated variables are presented in table 2 . In general, asthma was more prevalent among 4-6-year-old children whose mothers were less educated, suffered from asthma, were smoking during pregnancy or were exposed to environment tobacco smoke, were living in a flat or whose children used antibiotics during the first year of life. Children with asthma spent less time in green space than healthy children.

\section{Association between green space and asthma}

The proportions of children with asthma had a tendency to increase with an increasing median NDVI in different buffer sizes (table 3). In addition, the NDVI higher than the median was associated with a $27 \%, 19 \%$ and $32 \%$ increase in the probability of asthma within 100, 300 and $500 \mathrm{~m}$ of residences, respectively, in unadjusted models. After adjustment, the associations were similar, yet not statistically significant. The associations of NDVI IQR in NDVI-300 $\mathrm{m}$ and NDVI-500 $\mathrm{m}$ buffer sizes with asthma were similar in magnitude. However, an increase in the IQR of green space, using the NDVI-100 $\mathrm{m}$ buffer size, was associated with a statistically significant increase in the asthma risk after adjustment for parental asthma, maternal education, age at childbirth, smoking during pregnancy, breastfeeding, antibiotic use during the first year of life, keeping a cat during the past 12 months, living in a flat and time spent in green space (aOR 1.43, $95 \% 1.10$ to 1.85 ). The distance to a park was not associated with the increased risk of asthma in the unadjusted and adjusted models.

\section{Stratified analysis by surrounding greenness and distance to city parks}

Seeking to distinguish the effect of greenness level (assessed as NDVI) and park effect and assess their joint effect on the risk of asthma among children, we conducted stratified analysis. In this analysis, the interaction term included the NDVI- $100 \leq$ median as a reference, and the distance to a city park as the effect modifier 


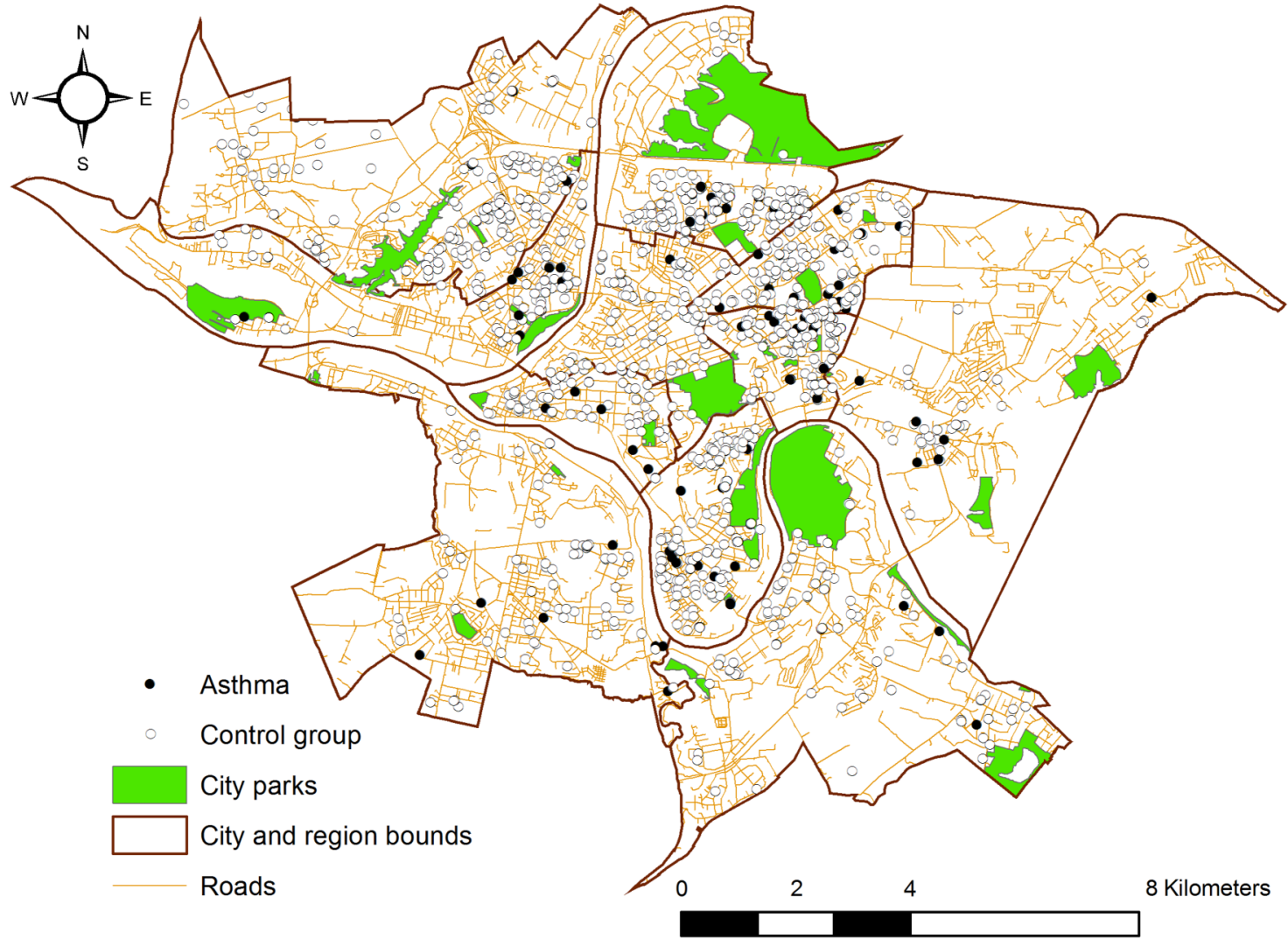

Figure 1 Spatial distribution of study population (asthma cases and controls), neighbourhood walkability and Kaunas city parks locations.

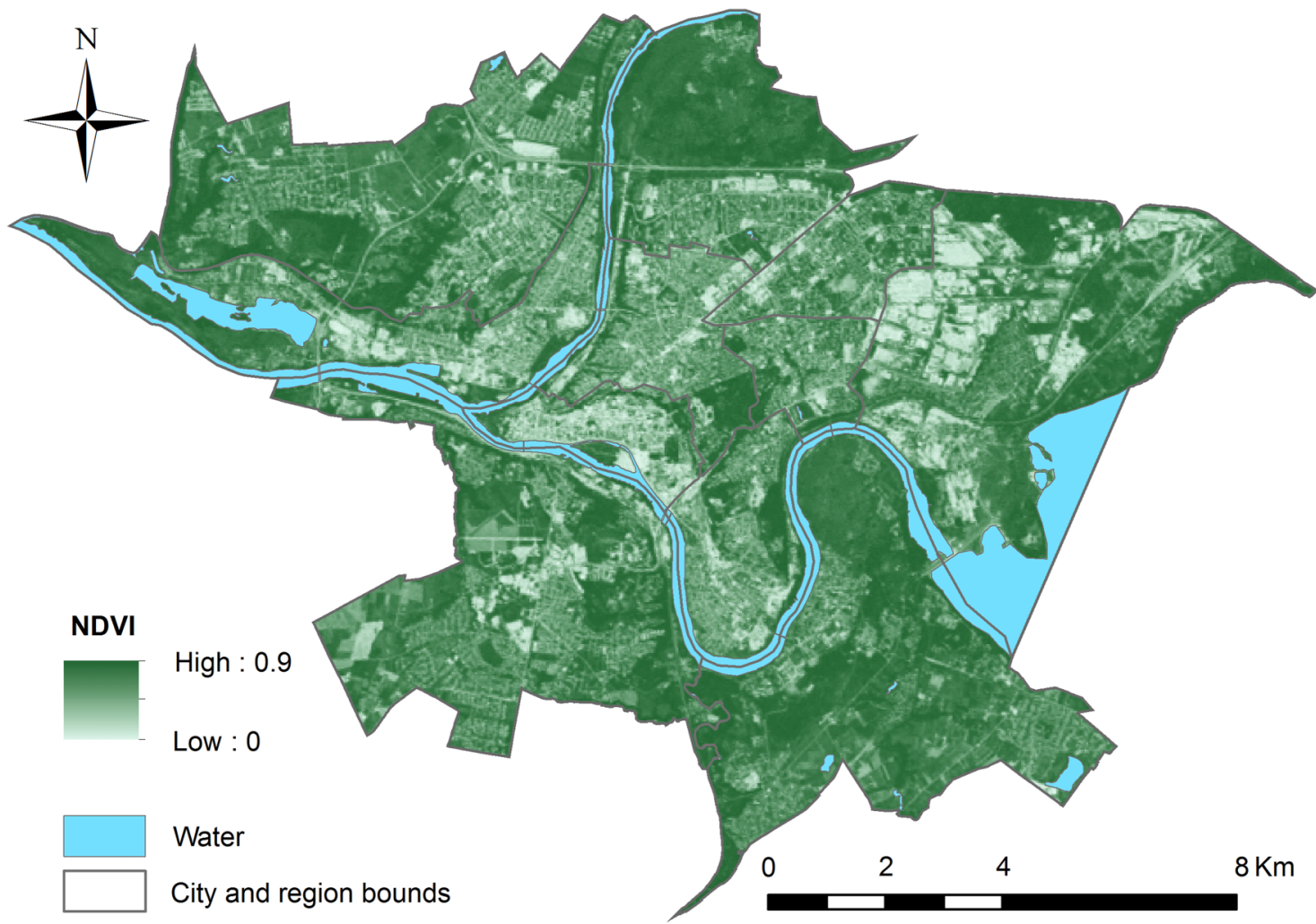

Figure 2 Spatial distribution of greenness level for the Kaunas city measured with satellite-derived NDVI. NDVI, Normalised Difference Vegetation Index. 
Table 1 Distribution of residential greenness level in different buffer size

\begin{tabular}{lllll}
\hline Variable $(\mathbf{m})$ & $\begin{array}{l}\text { 25th } \\
\text { centile }\end{array}$ & Median & $\begin{array}{l}\text { 75th } \\
\text { centile }\end{array}$ & IQR \\
\hline NDVI-100 & 0.489 & 0.553 & 0.599 & 0.110 \\
NDVI-300 & 0.494 & 0.548 & 0.602 & 0.109 \\
NDVI-500 & 0.491 & 0.547 & 0.608 & 0.116 \\
\hline
\end{tabular}

NDVI, Normalised Difference Vegetation Index.

Table 2 Distribution of variables according to children's asthma status

\begin{tabular}{|c|c|c|}
\hline Variables & $\begin{array}{l}\text { Asthma yes } \\
\mathrm{N}(\%) \\
(\mathrm{N}=112)\end{array}$ & $\begin{array}{l}\text { Asthma no } \\
\mathrm{N}(\%) \\
(\mathrm{N}=1377)\end{array}$ \\
\hline \multicolumn{3}{|l|}{ Mother's age at childbirth } \\
\hline$\leq 30$ & $71(63.39)$ & $923(67.03)$ \\
\hline 31 and more & $41(36.61)$ & 454 (32.97) \\
\hline \multicolumn{3}{|l|}{ Maternal education status } \\
\hline Low (10 or fewer years) & $33(29.46)^{\star}$ & $274(19.90)$ \\
\hline $\begin{array}{l}\text { Medium and high } \\
\text { (>10 years) }\end{array}$ & $79(70.54)$ & $1103(80.10)$ \\
\hline \multicolumn{3}{|l|}{ Socioeconomic status } \\
\hline Low & $35(31.25)$ & $366(26.58)$ \\
\hline Medium, high & 77 (68.75) & $1011(73.42)$ \\
\hline \multicolumn{3}{|c|}{ Maternal smoking during pregnancy } \\
\hline No & $98(87.50)$ & $1278(92.81)$ \\
\hline Yes & $14(12.50)$ & $99(7.19)$ \\
\hline \multicolumn{3}{|l|}{ Maternal passive smoking } \\
\hline No & $66(58.93)$ & $890(64.63)$ \\
\hline Yes & $46(41.07)$ & $487(35.37)$ \\
\hline \multicolumn{3}{|l|}{ Gas cooking } \\
\hline No & $34(30.36)$ & $501(36.38)$ \\
\hline Yes & $78(69.64)$ & $876(63.62)$ \\
\hline \multicolumn{3}{|l|}{ Living in a flat } \\
\hline No & $41(36.60)$ & $568(41.25)$ \\
\hline Yes & $71(63.40)$ & $809(58.75)$ \\
\hline \multicolumn{3}{|l|}{ Sex } \\
\hline Male & $63(56.25)$ & $675(49.02)$ \\
\hline Female & 49 (43.75) & $702(50.98)$ \\
\hline \multicolumn{3}{|l|}{ Birth order } \\
\hline 1 & $56(50.0)$ & $766(55.62)$ \\
\hline 2 and more & $56(50.0)$ & $611(44.38)$ \\
\hline \multicolumn{3}{|l|}{ Breastfeeding } \\
\hline No & $11(9.82)$ & $88(6.39)$ \\
\hline Yes & $101(90.18)$ & $1289(93.61)$ \\
\hline \multicolumn{3}{|c|}{ Paracetamol use during the first year of life } \\
\hline No & $27(24.11)$ & $426(30.94)$ \\
\hline Yes & $85(75.89)$ & $951(69.06)$ \\
\hline \multicolumn{3}{|c|}{ Antibiotic use during the first year of life } \\
\hline No & $50(44.64)$ & $924(67.10)$ \\
\hline Yes & $62(55.36)^{\star}$ & $453(32.90)$ \\
\hline \multicolumn{3}{|l|}{ Asthma in parents } \\
\hline No & $91(81.25)$ & $1300(94.41)$ \\
\hline Yes & $21(18.75)^{\star}$ & $77(5.59)$ \\
\hline \multicolumn{3}{|c|}{ Time spent in green space (hours) } \\
\hline$\leq 5$ & $70(62.50)$ & 753 (54.68) \\
\hline$>5$ & $42(37.50)$ & 624 (45.32) \\
\hline
\end{tabular}

(table 4). In the sensitivity analysis, asthma risk estimates were essentially unchanged after adjustment for maternal smoking during pregnancy, antibiotic use during the first year of life, parental asthma, maternal education, mother's age at childbirth, keeping a cat during the past 12 months, breastfeeding, living in a flat. After additionally adjusting for PM2.5, and $\mathrm{NO}_{2}$, we found the strength of association to be $15 \%$ higher among children residing close to city parks $(\leq 1000 \mathrm{~m})$ in areas with low exposure to green spaces (NDVI-100 $\mathrm{m}$ below median); however, the additive park distance effect for an increased risk of asthma was not statistically significant (adjusted OR 1.15, 95\% CI 0.50 to 2.62).

When comparing the joint effect of NDVI below the median with that above the median within the $100 \mathrm{~m}$ buffer size from home among children with low park exposure (distance to a city park $>1000 \mathrm{~m}$ ), we found that the risk of asthma increased by $47 \%$, and for those living closer to a park, the risk of asthma increased by $27 \%$ (adjusted OR $1.27,95 \%$ CI 0.56 to 2.86 ). The unadjusted and adjusted results showed that higher greenness levels measured within a $100 \mathrm{~m}$ buffer size of the home had a higher effect on the risk of asthma among 4-6-year-old children than residence closer than $1000 \mathrm{~m}$ to a city park did; however, these results were not statistically significant.

\section{DISCUSSION}

The results of this nested case-control study present some evidence for the association of the surrounding greenness levels, the distance from the place of residence to city parks, and clinically diagnosed asthma in children. The proportions of children with asthma had a tendency to increase with an increasing median NDVI in different buffer sizes. Regression models adjusted for covariates indicated that an interquartile increase in greenness within $100 \mathrm{~m}$ of the surrounding maternal home address was associated with a statistically significant $43 \%$ increase in asthma risk at 4-6 years of age, while close residence to a city park was not statistically significantly associated with asthma risk.

No individual-level case-control studies are available to compare with this finding; however, these patterns of the associations are similar to the previous reports on the association between greenness and allergies. A crosssectional study of a population-based sample of 3178 schoolchildren (9-12 years old) found a higher relative prevalence of current asthma (OR 1.60, 95\% CI 1.09 to 2.36) associated with living within $300 \mathrm{~m}$ of parks ${ }^{13}$ or higher street tree canopy coverage ${ }^{10}{ }^{10}$ However, no statistically significant relationships between the tree canopy coverage and asthma rates were found in a Texas study. ${ }^{14}$ Previously, in an ecological design study, an inverse association was observed between an increase in street tree density and a decrease in the prevalence of asthma among children in urban areas such as New York City, ${ }^{15}$ yet this does not permit an inference that trees are 
Table 3 Unadjusted and adjusted effects of green spaces as asthma ORs (OR) and 95\% Cls (Cl)

\begin{tabular}{|c|c|c|c|}
\hline Exposure variables & $\begin{array}{l}\text { Asthma yes } \\
\text { N (\%) }\end{array}$ & Unadjusted OR (95\% Cl) & Adjusted† OR (95\% Cl) \\
\hline \multicolumn{4}{|l|}{ NDVI-100 } \\
\hline$\leq$ Median & $50(6.7)$ & Reference & Reference \\
\hline >Median & $62(8.4)$ & $1.27(0.85$ to 1.91$)$ & 1.19 (0.79 to 1.79$)$ \\
\hline IQR‡ & & $1.43^{*}(1.12$ to 1.82$)$ & $1.43^{*}(1.10$ to 1.85$)$ \\
\hline \multicolumn{4}{|l|}{ NDVI-300 } \\
\hline$\leq$ Median & $52(6.9)$ & Reference & Reference \\
\hline >Median & $60(8.1)$ & $1.19(0.79$ to 1.78$)$ & $1.17(0.78$ to 1.76$)$ \\
\hline IQR & & $1.21(0.95$ to 1.56$)$ & $1.23(0.94$ to 1.61$)$ \\
\hline \multicolumn{4}{|l|}{ NDVI-500 } \\
\hline$\leq$ Median & $49(6.6)$ & Reference & Reference \\
\hline >Median & $63(8.5)$ & $1.32(0.88$ to 1.98$)$ & 1.39 (0.92 to 2.10$)$ \\
\hline IQR $\ddagger$ & & 1.15 (0.88 to 1.50$)$ & 1.18 (0.88 to 1.57$)$ \\
\hline \multicolumn{4}{|c|}{ Distance to a city park (m) } \\
\hline$>1000$ & $21(7.7)$ & Reference & Reference \\
\hline$\leq 1000$ & $91(7.5)$ & $0.97(0.59$ to 1.59$)$ & $0.96(0.55$ to 1.68$)$ \\
\hline \multicolumn{4}{|c|}{$\begin{array}{l}\text { * } p<0.05 . \\
\dagger \text { Adjusted for: parental asthma, maternal education, age at childbirth, smoking during pregnancy, breastfeeding, antibiotic use during the first } \\
\text { year of life, keeping a cat during the past } 12 \text { months, living in a flat, time spent in green space. } \\
\text { flQR increase. } \\
\text { NDVI, Normalised Difference Vegetation Index. }\end{array}$} \\
\hline
\end{tabular}

causally related to the prevalence of asthma at the individual level.

The difference in study design and greenness (tree species and park plant biodiversity) may have an impact on the observed different levels of associations between residential distance to forests and to parks and the prevalence of childhood asthma. ${ }^{1324}$ Also, a difference between forest and park flora and the composition of ambient pollen concentrations could explain these variations. $^{10} 1225$ A clinical study in Korea showed that shortterm exposure to forest environment may have positive clinical and immunological effects in children with allergic diseases who were living in the urban community. ${ }^{26}$ Furthermore, residential location, social factors, age and education are likely to have an impact on the use of green spaces and the course of allergic diseases. ${ }^{27}{ }^{28} \mathrm{~A}$ cohort study in Germany found area-specific heterogeneous associations across urban and rural study areas between mean greenness in a $500 \mathrm{~m}$ buffer around the home address at 10 years and childhood allergies: positively associated with allergic rhinitis and eyes and nose symptoms in urban areas and negatively associated in rural areas. ${ }^{29}$

There is some evidence of health benefits to children associated with outdoor activities and time spent in a natural environment such as a park or other recreational area. By reducing noise and transport-related air pollution levels, enhancing physical activity and minimising a sedentary lifestyle, greenness may have a positive impact on the reduction of psychophysiological stress in children residing in poorer housing and environmental conditions. $^{30-32}$

Some of our observed associations between higher residential greenness levels and an increased risk of asthma are consistent with the results of the previous studies, while others are not. In a New York city cohort study, asthma among 7-year-old children increased by $17 \%$ per SD increase of tree canopy coverage (adjusted risk ratios $1.17,95 \%$ CI 1.02 to 1.33$).{ }^{14}$ The results of this study are in line with those of the previous studies,

Table 4 The joint effect of NDVI-100 m buffer and distance to a city park on the clinically diagnosed asthma in 4-6-year-old children

\begin{tabular}{lccc}
\hline $\begin{array}{l}\text { One hundred metres buffer NDVI and } \\
\text { distance to a city park }(\mathbf{m})\end{array}$ & $\begin{array}{l}\text { Asthma cases } \\
\text { No (\%) }\end{array}$ & Unadjusted OR & Adjusted* OR (95\% Cl) \\
\hline NDVI-100 $\leq$ median and to city park $>1000$ & $9(6.5)$ & Reference & Reference \\
NDVI-100 $\leq$ median and to city park $\leq 1000$ & $41(6.7)$ & $1.04(0.47$ to 2.37) & $1.15(0.50$ to 2.62$)$ \\
NDVI-100 $>$ median and to city park $>1000$ & $12(9.0)$ & $1.42(0.54$ to 3.81$)$ & $1.47(0.56$ to 3.87$)$ \\
NDVI-100 $>$ median and to city park $\leq 1000$ & $50(8.2)$ & $1.30(0.60$ to 2.91) & $1.27(0.56$ to 2.86) \\
\hline
\end{tabular}

${ }^{\star}$ Adjusted for: maternal smoking during pregnancy, antibiotic use during the first year of life, parental asthma, maternal education, mother's age at childbirth, keeping a cat during the past 12 months, breastfeeding, living in a flat, PM2.5 and $\mathrm{NO}_{2}$.

NDVI, Normalised Difference Vegetation Index. 
suggesting that high exposure to green spaces may increase the risk of allergic conditions and the prevalence of asthma through the production of pollen. ${ }^{10} 12$ On the other hand, the decrease in the biodiversity of the living environment has been associated with dysfunctions of the immune system and increasing allergies. ${ }^{24} 33$ A cross-sectional study of schoolchildren in Sabadell, Spain, concluded that an IQR increase in residential surrounding greenness across a $100 \mathrm{~m}$ buffer around participants' home addresses was not associated with current asthma (OR $1.00,95 \%$ CI 0.82 to 1.21$).{ }^{13}$ No statistically significant relationships between NDVI and the prevalence of asthma were found in an ecological study which did not control for possible confounding covariates. ${ }^{14}$ However, cohorts from Finland and Estonia reported that the amount of green environment around homes was inversely associated with the risk of atopic sensitisation in children aged 6 years and older. ${ }^{16}$ The authors concluded that environmental biodiversity affects the composition of the human skin microbiota, influences immune tolerance, and decreases the risk of atopic sensitisation in children.

We found stronger associations for asthma among children exposed to higher surrounding greenness than for those living close to city parks, even though the child with asthma spent less time in green space than healthy children. These associations did not change after adjusting for other individual and environment variables, including ambient PM2.5 and $\mathrm{NO}_{2}$, suggesting that residential greenness has an impact on children asthma prevalence. However, the findings suggest that visits to green space has positive effect on children health through psychophysiological stress reduction and increased physical activity, nevertheless that there is no clear understanding mechanisms of the impact of the exposure to green spaces on allergy and asthma in children. ${ }^{1134}$ The underlying mechanisms for the positive surrounding greenness impact on children health may be partially explained by the physiological study's findings of healthy participants, indicating that walking in the forest environment can facilitate homeostasis through positive effects on the central and autonomic nervous system and endocrine system. ${ }^{35}{ }^{36}$ In addition, immunology research shows that green spaces can increase human immune function by facilitating the activity of macrophage cells. ${ }^{37}$ Children with poorly controlled asthma, chronic airways inflammation and episodic respiratory symptoms have dysfunctional alveolar macrophage phagocytic immune response $;^{38} 39$ therefore, green space by facilitating homeostasis may have a different effect. Heterogeneous associations of residential greenness with allergic conditions further emphasise that the effect of green spaces on health is complex and needs to be further investigated across studies that vary in the composition of green spaces, air quality and population groups.

Our study faced some limitations. In this study, the use of one NDVI image and straight-line distance rather than the road network for park accessibility may produce green space exposure measurement error; assuming that this error is non-differential for asthmatic and non-asthmatic children, it might attenuate longterm exposure effect estimates. However, our study used the same research conditions and objective environmental measurements, including individual yearly mean air pollutants exposure. Measurement errors may also be present in the evaluation of health outcomes, and the estimations of the associations may be skewed by unmeasured confounding data obtained by parents' responses to questions on their children's asthma, as well as by variables that could have resulted in the misclassification of health outcomes and might have attenuated the strengths of the observed associations. However, this limitation is assumed to be random. The results are also affected by the small sample sizes, albeit large enough, to detect some significant effects. However, the small sample sizes used in the stratified analysis may have an impact on the ability to detect a statistically significant relationship.

The current study had the advantage of using a large number of covariates gathered during the interview, and thus may individually control for covariates associated with asthma, such as smoking, maternal diseases, education and others. Another advantage is the objective estimation of exposure to green spaces and major ambient air pollutants at the individual level and the possibility to avoid exposure misclassification associated with participants' mobility. Even though many covariates in the analyses were considered, residual confounding remains possible. Antenatal allergic sensitisation, which is the most common precursor to the development of asthma and polymorphisms in inflammation genes, might affect the association between environmental exposures and the risk of asthma in early childhood. ${ }^{7}{ }^{40}$ Additional associations that may be considered in future research include chronic stress in children and the interaction between the behavioural, genetic and environmental risk factors that may be related to asthma. The generalisability of our findings may, however, be somewhat limited owing to possible differences in surrounding greenness exposure and park biodiversity.

\section{CONCLUSIONS}

This study demonstrates positive associations between surrounding greenness quantity within the buffer of $100 \mathrm{~m}$ from each child's home and the prevalence of asthma among 4-6-year-old children, and this association persists after adjusting for individual-level covariates and exposures to air pollution. Although findings in the stratified analyses on the joint effect of the surrounding greenness and the distance to city parks lack statistical significance and require further confirmation by other studies, they highlight the need for more research on the effect of the natural environment on children's health. Equivocal and inconsistent results from previous 
epidemiological studies on green space exposure effects on asthma may be attributable to the crude exposure assessment that did not adequately represent the individual exposure, differences in subgroups susceptibility or health behaviour. Future investigation of causal relationship between surrounding greenness and childhood asthma could provide preventive measures for allergy management and intervention programmes, particularly of behavioural change and stress management.

Contributors SA performed the statistical analysis, drafted the methods and was the lead writer. RG conceived the idea, designed the study and revised the manuscript. JK assisted with the writing of the manuscript and revised the manuscript. $A B$ assisted with the writing and revision of the manuscript. $A D$ modelled the air pollution data, created GIS maps and revised the manuscript. MJN conceptualised and supervised the analyses, and critically reviewed the manuscript. All authors critically reviewed and revised the manuscript, and approved the final version of the manuscript as submitted.

Funding This work was supported in part by the European Commission grant number FP7-282996, and the grant of Lithuanian Agency for Science Innovation and Technology 2014-10-13 No 31V-66.

Competing interests None declared.

Patient consent Obtained.

Ethics approval This study was approved by the Lithuanian Bioethics Committee.

Provenance and peer review Not commissioned; externally peer reviewed.

Data sharing statement No additional data are available.

Open Access This is an Open Access article distributed in accordance with the Creative Commons Attribution Non Commercial (CC BY-NC 4.0) license, which permits others to distribute, remix, adapt, build upon this work noncommercially, and license their derivative works on different terms, provided the original work is properly cited and the use is non-commercial. See: http:// creativecommons.org/licenses/by-nc/4.0/

\section{REFERENCES}

1. O'Connell EJ. The burden of atopy and asthma in children. Allergy 2004;59:7-11.

2. Heinrich $\mathrm{J}$. Influence of indoor factors in dwellings on the development of childhood asthma. Int J Hyg Environ Health 2011;214:1-25.

3. Asher MI, Montefort S, Björkstén B, et al. Worldwide time trends in the prevalence of symptoms of asthma, allergic rhino conjunctivitis, and eczema in childhood: ISAAC Phases One and Three repeat multicounty cross-sectional surveys. Lancet 2006;368:733-43.

4. Kudzyte J, Griska E, Bojarskas J. Time trends in the prevalence of asthma and allergy among 6-7-year-old children. Results from ISAAC phase I and III studies in Kaunas, Lithuania. Medicina 2008;44:944-52.

5. Haahtela T, Holgate S, Pawankar R, et al. The biodiversity hypothesis and allergic disease: world allergy organization position statement. World Allergy Organ J 2013;6:1-18.

6. Haley KJ, Lasky-Su J, Manoli SE, et al. RUNX transcription factors: association with pediatric asthma and modulated by maternal smoking. Am J Physiol Lung Cell Mol Physiol 2011;301:L693-701.

7. Sørensen $\mathrm{M}$, Allermann L, Vogel $\mathrm{U}$, et al. Polymorphisms in inflammation genes, tobacco smoke and furred pets and wheeze in children. Pediatr Allergy Immunol 2009;20:614-23.

8. Daley D, Lemire M, Akhabir L, et al. Analyses of associations with asthma in four asthma population samples from Canada and Australia. Human Genetic 2009;125:445-59.

9. Penard-Morand C, Raherison C, Charpin D, et al. Long-term exposure to close-proximity air pollution and asthma and allergies in urban children. Eur Respir J 2010;36:33-40.

10. Lovasi GS, O'Neil-Dunne JPM, Lu JWT, et al. Urban tree canopy and asthma, wheeze, rhinitis, and allergic sensitization to tree pollen in a New York City birth cohort. Environ Health Perspect 2013;121:494-500.
11. Nieuwenhuijsen MJ, Kruize H, Gidlow $\mathrm{C}$, et al. Positive health effects of the natural outdoor environment in typical populations in different regions in Europe (PHENOTYPE): a study programme protocol. BMJ Open 2014;4:e004951.

12. DellaValle CT, Triche EW, Leaderer BP, et al. Effects of ambient pollen concentrations on frequency and severity of asthma symptoms among asthmatic children. Epidemiology 2012;23:55-63.

13. Dadvand P, Villanueva CM, Font-Ribera L, et al. Risks and benefits of green spaces for children: a cross-sectional study of associations with sedentary behaviour, obesity, asthma, and allergy. Environ Health Perspect 2014;122:1329-35.

14. Pilat MA, McFarland A, Snelgrove A, et al. The effect of tree cover and vegetation on incidence of childhood asthma in metropolitan statistical areas of Texas. Hort Technology 2012;22:631-7.

15. Lovasi GS, Quinn JW, Neckerman KM, et al. Children living in areas with more street trees have lower prevalence of asthma. J Epidemiol Community Health 2008;62:647-9.

16. Ruokolainen L, von Hertzen L, Fyhrquist N. Green areas around homes reduces atopic sensitization in children. Allergy 2015;70:195-202.

17. Sugiyama T, Leslie E, Giles-Corti B, et al. Associations of neighborhood greenness with physical and mental health: do walking, social coherence and local social interaction explain the relationships? J Epidemiol Community Health 2008;62:9-14.

18. Maas J, Verheij RA, de Vries S, et al. Morbidity is related to a green living environment. J Epidemiol Community Health 2009;63:967-73.

19. Tamosiunas A, Grazuleviciene R, Luksiene D, et al. Accessibility and use of urban green spaces, and cardiovascular health: findings from a Kaunas cohort study. Environ Health 2014;13:20.

20. Grazuleviciene R, Danileviciute A, Dedele A, et al. Surrounding greenness, proximity to city parks and pregnancy outcomes in Kaunas cohort study. Int J Hyg Environ Health 2015;218:358-65.

21. European Commision. Expert group on the urban environment. towards a local sustainability profile-European Common Indicators. Luxembourg: Office for Official Publications of the European Communities, 2001.

22. Januskevicius L. Investigation of introduced dendroflora of old parks in Middle Lithuania. Dendrologia Lithuaniae 2002;6:53-68.

23. de Hoogh K, Wang M, Adam M, et al. Development of land use regression models for particle composition in twenty study areas in Europe. Environ Sci Technol 2013;47:5778-86.

24. Hanski I, von Hertzen L, Fyhrquist N, et al. Environmental biodiversity, human microbiota, and allergy are interrelated. Proc Natl Acad Sci USA 2012;109:8334-9.

25. Cariñanos $P$, Casares-Porcel $M$. Urban green zones and related pollen allergy: a review. Some guidelines for designing spaces with low allergy impact. Landsc Urban Plan 2011;101:205-14.

26. Seo SC, Park SJ, Park CW, et al. Clinical and immunological effects of a forest trip in children with asthma and atopic dermatitis. Iran $J$ Allergy Asthma Immunol 2015;14:28-36.

27. Payne LL, Mowen AJ, Orsega-Smith E. An examination of park preferences and behaviours among urban residents: the role of residential location, race, and age. Leis Sci 2002;24:181-98.

28. Roovers $P$, Hermy M, Gulinck H. Visitor profile, perceptions and expectations in forest from a gradient of increasing urbanisation in central Belgium. Landsc Urban Plan 2002;59:129-45.

29. Fuertes E, Markevych I, von Berg A, et al. Greenness and allergies: evidence of differential associations in two areas in Germany. $\checkmark$ Epidemiol Community Health 2014;68:787-90.

30. McCurdy LE, Winterbottom KE, Mehta SS, et al. Using nature and outdoor activity to improve children's health. Curr Probl Pediatr Adolesc Health Care 2010;40:102-17.

31. Balseviciene B, Sinkariova L, Grazuleviciene R, et al. Impact of residential greenness on preschool children's emotional and behavioural problems. Int J Environ Res Public Health 2014:11:6757-70.

32. Scharte M, Bolte G. Children of single mothers: health risks and environmental stress. Gesundheitswesen 2012;74:123-31.

33. Rook GA. Regulation of the immune system by biodiversity from the natural environment: an ecosystem service essential to health. Proc Natl Acad Sci USA 2013;110:18360-7.

34. Harting T, Mitchell R, De Vries S, et al. Nature and health. Ann Rev Public Health 2014;35:207-28.

35. Tsunetsugu $\mathrm{Y}$, Park BJ, Ishii $\mathrm{H}$, et al. Physiological effects of Shinrin-yoku (taking in the atmosphere of the forest) in an old-growth broadleaf forest in Yamagata Prefecture, Japan. J Physiolo Anthropol 2007;26:135-42.

36. Lee $\mathrm{Y}$, Tsunetsugu $\mathrm{Y}$, Takayama N, et al. Influence of forest therapy on cardiovascular relaxation in young adults. Evid Based Complement Alternat Med 2014;2014:1-7. 
37. Li Q, Morimoto K, Kobayashi M, et al. A forest bathing trip increases human natural killer activity and expression of anti-cancer proteins in female subjects. J Biol Regul Homeos Agents 2008;22:45-55.

38. Hodge S, Upham JW, Pizzutto S, et al. Is alveolar macrophage phagocytic dysfunction in children with protracted bacterial bronchitis a forerunner to bronchiectasis? Chest 2016;149:508-15.
39. Fitzpatrick AM, Holguin F, Teague WG, et al. Alveolar macrophage phagocytosis is impaired in children with poorly controlled asthma. $J$ Allergy Clin Immunol 2008;121:1372-8.

40. Sbihi $\mathrm{H}$, Allen RW, Becker A, et al. Exposure to traffic-related air pollution and atopy at 1 year of age in a multi-center Canadian Birth Cohort Study. Environ Health Perspect 2015;123:902-8. 